Article

\title{
The Role of the Arginine in the Conserved N-Terminal Domain RLFDQxFG Motif of Human Small Heat Shock Proteins HspB1, HspB4, HspB5, HspB6, and HspB8
}

\author{
Vladislav M. Shatov ${ }^{1}$, Stephen D. Weeks ${ }^{2}$ (i), Sergei V. Strelkov ${ }^{2}$ (i) and Nikolai B. Gusev ${ }^{1, *}$ (i) \\ 1 Department of Biochemistry, School of Biology, Moscow State University, Moscow 119991, Russia; \\ shatovm@inbox.ru \\ 2 Laboratory of Biocrystallography, Department of Pharmaceutical and Pharmacological Sciences, KU Leuven, \\ Leuven 3000, Belgium; stephen.weeks@kuleuven.be (S.D.W.); sergei.strelkov@kuleuven.be (S.V.S.) \\ * Correspondence: NBGusev@mail.ru; Tel.: +7-495-939-2747
}

Received: 17 June 2018; Accepted: 17 July 2018; Published: 20 July 2018

\begin{abstract}
Although the N-terminal domain of vertebrate small heat shock proteins (sHsp) is poorly conserved, it contains a core motif preserved in many members of the sHsp family. The role of this RLFDQxFG motif remains elusive. We analyzed the specific role of the first arginine residue of this conserved octet sequence in five human sHsps (HspB1, HspB4, HspB5, HspB6, and HspB8). Substitution of this arginine with an alanine induced changes in thermal stability and/or intrinsic fluorescence of the related HspB1 and HspB8, but yielded only modest changes in the same biophysical properties of HspB4, HspB5, and HspB6 which together belong to another clade of vertebrate sHsps. Removal of the positively charged Arg side chain resulted in destabilization of the large oligomers of HspB1 and formation of smaller size oligomers of HspB5. The mutation induced only minor changes in the structure of HspB4 and HspB6. In contrast, the mutation in HspB8 was accompanied by shifting the equilibrium from dimers towards the formation of larger oligomers. We conclude that the RLFDQXFG motif plays distinct roles in the structure of several sHsp orthologs. This role correlates with the evolutionary relationship of the respective sHsps, but ultimately, it reflects the sequence context of this motif.
\end{abstract}

Keywords: small heat shock proteins; oligomer structure; chaperone-like activity; disease-related mutations

\section{Introduction}

Small heat shock proteins (sHsps) form a large family of chaperones expressed in all kingdoms of life including viruses, bacteria, fungi, plants, and animals [1,2]. Monomers of sHsps have a molecular weight ranging from 13 up to $43 \mathrm{kDa}$ and contain a conserved $\alpha$-crystallin domain (ACD) consisting of 80-100 residues that form a compact $\beta$-sandwich [3-5]. The ACD is flanked by a poorly ordered $\mathrm{N}$-terminal domain (NTD) and a comparatively shorter C-terminal domain (CTD). The latter can be further divided into the conserved (I/V/L)-X-(I/V/L) tripeptide (IXI) or C-terminal anchoring motif (CAM) [6], and the highly flexible and polar C-terminal extension (CTE) $[5,7,8]$. The ACD is responsible for formation of sHsp dimers, whereas the CTD mediates the interdimer interaction [7-9]. The sHsp homo- or heterodimers are the building blocks of larger oligomers [10,11]. In addition, sHsp monomers were also shown to participate in the dynamic association of larger homo- and heterooligomers [8]. Oligomerization plays an important role in the regulation of chaperone-like activity and interaction of sHsp with their protein targets [12,13]. 
The NTD is involved in higher order assembly of sHsps and the formation of heterooligomers. The NTD is enriched in Pro and Arg residues, is highly susceptible to proteolysis [14], and often contains multiple phosphorylation sites [15-18]. Most of the NTD is believed to be intrinsically disordered [19]. The NTD contains little secondary structure, although short $\alpha$-helices and $\beta$-structural elements were observed in plant and yeast sHsps [20,21]. While the high degree of disorder makes it difficult to investigate the structural organization of the NTD, various approaches were used to analyze its functional role. Deletion of certain parts of the NTD [22-25], domain swapping [26,27], replacement of certain residues [28], and production of phosphomimicking mutants [12,16] have yielded a complex yet intriguing picture. At the same time, large deletions or domain swapping can induce dramatic changes in the overall sHsp assembly, and thus complicate unequivocal interpretation of the results. In addition, these experiments were mostly performed on single members of the sHsp family, predominantly on $\alpha \mathrm{A}$ - or $\alpha \mathrm{B}$-crystallins (HspB4 and HspB5, respectively) $[16,25,28]$ or on HspB6 [24,27], while extrapolation to other members of the sHsp family remains problematic.

The NTD of vertebrate sHSPs can be provisionally divided into four regions [29] (Figure 1A). The first region, corresponding to the immediate $\mathrm{N}$-terminal residues, is 20 amino acids long in the $\alpha$-crystallins (HspB4 and HspB5) and 25 residues in HspB1, HspB6, and HspB8. This region is enriched in hydrophobic and aromatic residues and contains a number of phosphorylation sites. The second region, comprising a further 12-15 residues, contains the RLFDQxFG motif that is highly conserved in most vertebrate sHsps except for HspB3 and HspB7, and modified in the case of HspB9 and HspB10 (Figure 1A). The third region, containing residues 42-58 of HspB1 and the corresponding residues of four other sHsps, is poorly conserved and again contains a number of hydrophobic and aromatic residues. HspB1 and HspB8 also contain the so-called P1 region which is lacking in HspB4, HspB5, and HpsB6 (Figure 1A). Dependent on the way the amino acid sequence alignment is performed, the fourth region (or probably extension of the third region) appears to include residues 75-90 of HspB1 or the corresponding residues in other sHsps (Figure 1A).

A

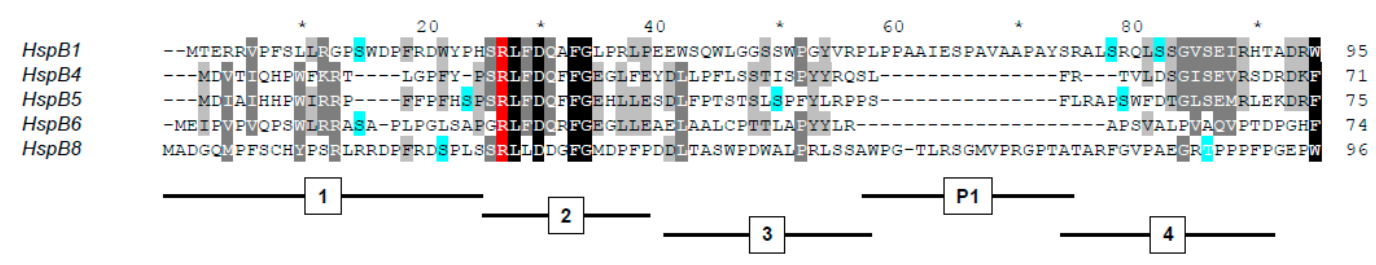

B

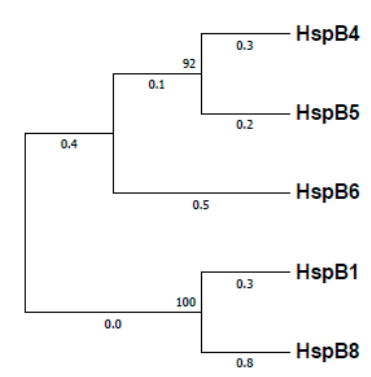

Figure 1. (A) Alignment of the N-terminal domains of five human small heat shock proteins. Conservative residues are marked by shades of grey, phosphorylation sites are marked blue, conservative Arg residue is marked red. The subdivision of the NTD is marked below the alignment. (B) Phylogeny of five human small heat shock proteins. The following sequences from Uniprot: P04792 (HspB1), P02489 (HspB4), P02511 (HspB5), O14558 (HspB6), Q9UJY1 (HspB8) were used. Multiple alignment was generated by Tcoffee (available online: http://tcoffee.crg.cat/). The tree was inferred by using the Maximum Likelihood method based on the JTT matrix-based model with MEGA7. The tree is drawn to scale, with branch lengths measured in the number of substitutions per site (next to the branches). All positions containing gaps and missing data were eliminated. 
The conserved RLFDQxFG motif was shown to play an important role in assembly and heterooligomerization [24,27]. In particular, the first Arg residue of this motif is preserved in sHsps in humans and many other vertebrates, suggesting that this residue may be important for maintaining various structural and functional properties. Here we aimed at a systematic examination of the role of this highly conserved Arg residue in HspB1, HspB4, HspB5, HspB6, and HspB8. After replacing this Arg by Ala in all five proteins, we have analyzed the effect of this replacement on quaternary structure and further biophysical properties. Interestingly, the largest impact of the mutation has been observed in human HspB8 which is particularly important due to disease-related mutations that were discovered in this protein and that correlate with several neurodegenerative and neuromuscular diseases [30-32].

\section{Results}

\subsection{Spectral Properties and Thermal Stability of sHsps and Their Point Mutants}

Under the expression and purification conditions employed, all recombinant proteins were solubly expressed and the combination of two chromatographic steps resulted in a highly purified preparation of both wild type proteins and their point mutants with replacement of the conserved Arg by Ala (Figure 2). In order to analyze the effect of the Arg/Ala substitution we investigated the spectral properties and thermal stability of the wild type proteins and their point mutants. In the case of HspB1, replacement of Arg27 by Ala had no effect on the absorbance and fluorescence spectrum (Figure 3A) or on the temperature of half-maximal unfolding measured by Trp fluorescence and detected at $68^{\circ} \mathrm{C}$ for both the wild type protein and its point mutant. However, the amplitude of temperature-induced aggregation of the wild type HspB1 was slightly larger than in the case of its R27A mutant (Figure 3B). Similarly, mutations R21A of HspB4, R22A of HspB5, or R27A of HspB6 had no significant effect either on absorbance in near UV range $(270-320 \mathrm{~nm})$ or fluorescence spectra or on temperature-induced aggregation of the analyzed proteins (Supplementary Material Figures S1 and S2).

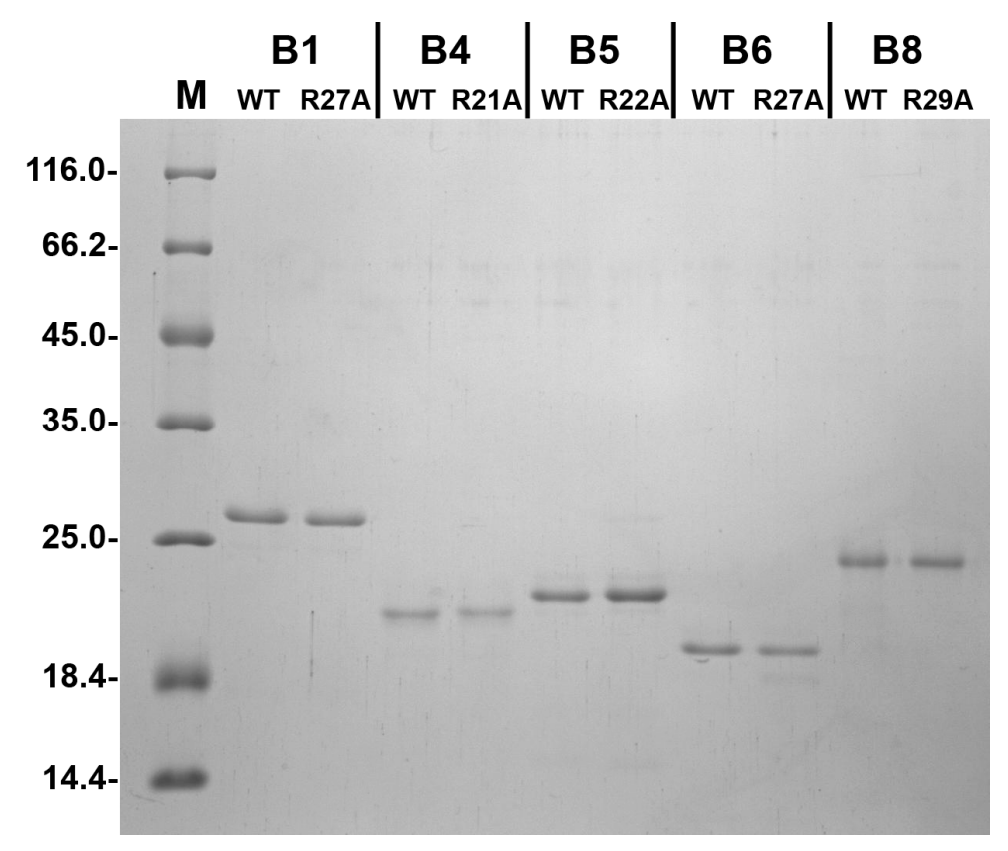

Figure 2. SDS electrophoresis of five human sHsp and their Ala mutants. Equal quantities $(\sim 1 \mu \mathrm{g})$ of each protein were loaded on each track. The position of markers $(\mathrm{M})$ and their molecular weight (in $\mathrm{kDa}$ ) are marked by dashes. 

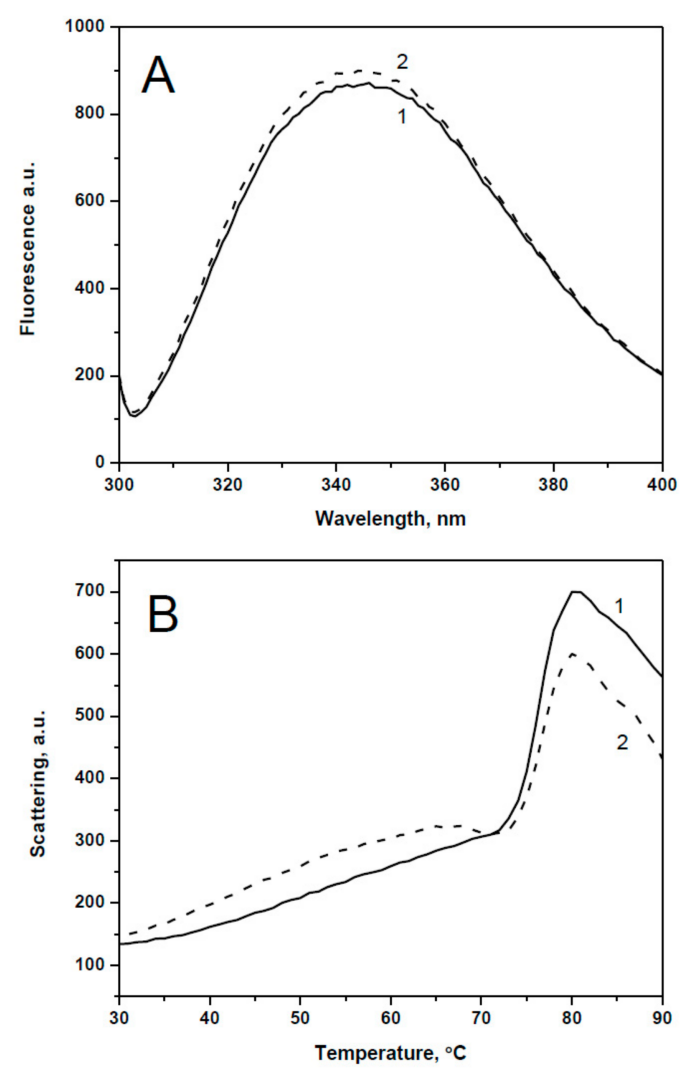

Figure 3. (A) Fluorescence spectra of the wild type HspB1 (1) and its R27A mutant (2) excited at $295 \mathrm{~nm}$ (slit width $5 \mathrm{~nm}$ ) and recorded in the range of 300-400 $\mathrm{nm}$ (slit width $5 \mathrm{~nm}$ ). (B). Temperature induced changes of light scattering measured at $340 \mathrm{~nm}$ of the wild type HspB1 (1) and its R27A (2) mutant.

Mutation R29A of HspB8 was accompanied by the largest changes in spectral properties of this protein. The absorbance spectrum of the wild type HspB8 is characterized by a shoulder at 290-295 nm and this shoulder disappeared in the spectrum of the mutant construct (Figure 4A). Correlated with this, the fluorescence maxima of the wild type HspB8 of $346 \mathrm{~nm}$ was blue-shifted to $339 \mathrm{~nm}$ in the case of R29A mutant indicating a more hydrophobic environment of Trp residues (Figure 4B). Temperature-induced aggregation of the R29A mutant started at a temperature significantly lower and was much more pronounced than that of the wild type HspB8 (Figure 4C).

Summing up, we might conclude that replacement of the conserved Arg induces spectral changes and / or changes of temperature-induced aggregation only in the case of HspB1 and HspB8, i.e., proteins containing the so-called P1 peptide at the end of the N-terminal domain (Figure 1A). The Arg/Ala substitution had no significant effect on the optical properties and/or temperature-induced aggregation of HspB4, HspB5 and HspB6, i.e., sHsp lacking this peptide. 

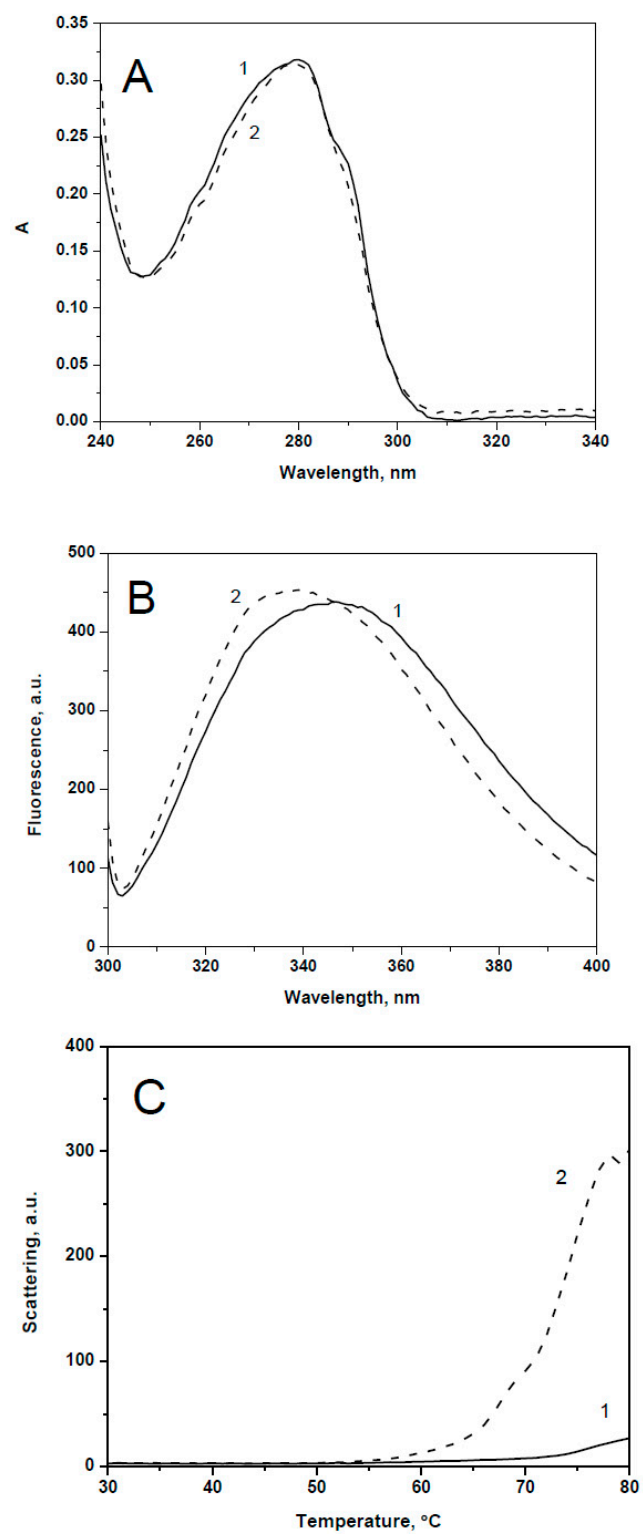

Figure 4. (A) Absorbance spectrum of the wild type HspB8 (1) and its R29A (2) mutant. (B) Fluorescence spectra of the wild type HspB8 (1) and its Ala mutant (2) excited at $295 \mathrm{~nm}$ (slit with $5 \mathrm{~nm}$ ) and recorded in the range of 300-400 $\mathrm{nm}$ (slit width $2.5 \mathrm{~nm}$ ). (C) Temperature induced changes of the light scattering measured at $340 \mathrm{~nm}$ of the wild type HspB8 (1) and its R29A (2) mutant.

\subsection{Effect of Arg/Ala Replacement on sHsp Quaternary Structure}

Size-exclusion chromatography (SEC), analytical ultracentrifugation (AUC), and dynamic light scattering (DLS) were used to investigate the quaternary structure of the different sHsp constructs. According to SEC, the wild type HspB1 formed stable high molecular weight oligomers with an apparent molecular weight of $\sim 540 \mathrm{kDa}$ independent of the quantity of protein loaded on the column (Figure 5A, Table 1). The oligomeric structure of the R27A mutant of HspB1 was dependent on the quantity of protein loaded on the column. At low concentrations, the R27A mutant formed two types of oligomer with apparent molecular weight of $80-90$ and $\sim 500 \mathrm{kDa}$, whereas at high concentrations this protein formed only the larger species (Figure 5B). The data of AUC indicate that both wild type HspB1 and its R27A mutant formed two types of oligomers with sedimentation coefficients in the range of 2-7 and 13-17 S (Figure 5C). The ratio between oligomers with high and low sedimentation coefficients was larger in the case of the wild type protein than in the case of the 
R27A mutant. The average hydrodynamic diameter of the wild type HspB1 (11.5 $\pm 0.5 \mathrm{~nm}$, number of measurements, $n=110)$ was slightly larger, than the corresponding diameter $(11.1 \pm 0.5 \mathrm{~nm}, n=130)$ of R27A mutant. A change that was statistically significant ( $t$ test value equal to 5 ).

Size-exclusion chromatography (SEC), analytical ultracentrifugation (AUC), and dynamic light scattering (DLS) were used to investigate the quaternary structure of the different sHsp constructs. According to SEC, the wild type HspB1 formed stable high molecular weight oligomers with an apparent molecular weight of $\sim 540 \mathrm{kDa}$ independent of the quantity of protein loaded on the column (Figure 5A, Table 1). The oligomeric structure of the R27A mutant of HspB1 was dependent on the quantity of protein loaded on the column. At low concentrations, the R27A mutant formed two types of oligomer with apparent molecular weight of 80-90 and $\sim 500 \mathrm{kDa}$, whereas at high concentrations this protein formed only the larger species (Figure 5B). The data of AUC indicate that both wild type HspB1 and its R27A mutant formed two types of oligomers with sedimentation coefficients in the range of 2-7 and 13-17 S (Figure 5C). The ratio between oligomers with high and low sedimentation coefficients was larger in the case of the wild type protein than in the case of the R27A mutant. The average hydrodynamic diameter of the wild type HspB1 (11.5 $\pm 0.5 \mathrm{~nm}$, number of measurements, $n=110)$ was slightly larger, than the corresponding diameter $(11.1 \pm 0.5 \mathrm{~nm}, n=130)$ of R27A mutant. A change that was statistically significant ( $t$ test value equal to 5 ).

The wild type HspB4 and its R21A mutant both formed stable large size oligomers with an apparent molecular weight of $\sim 590 \mathrm{kDa}$. The oligomeric size did not vary when changing the concentration of protein loaded on the column (Supplementary Material Figure S3). The data of AUC indicate that HspB4 forms a heterogeneous mixture of small 2-3 S and large 12-20 S oligomers. According to AUC, both the wild type HspB4 and its R21A mutant presented a mixture of large oligomers with sedimentation coefficients of 13, 16, and 19 S (Supplementary Material Figure S3). The small difference in oligomer distribution was confirmed by DLS data indicating that the hydrodynamic radius of the wild type HspB4 was equal to $12.1 \pm 0.6 \mathrm{~nm}(n=130)$, whereas the corresponding value for R21A mutant was equal to $11.8 \pm 0.9 \mathrm{~nm}(n=130)$.
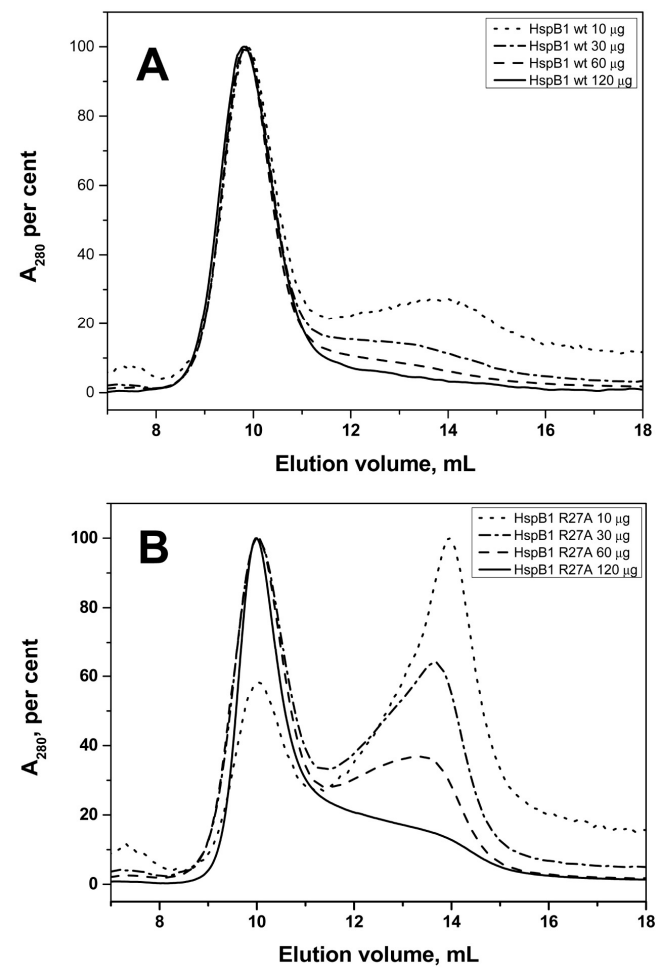

Figure 5. Cont. 


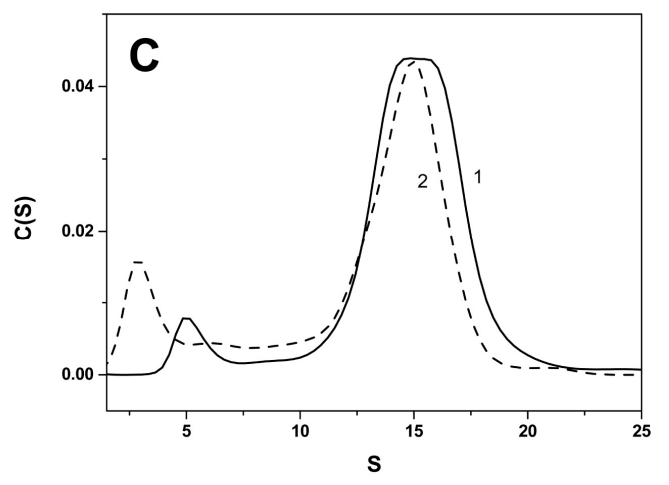

Figure 5. Effect of R27A mutation on quaternary structure of HspB1. Size-exclusion chromatography of the wild type HspB1 (A) and its R27A mutant (B) Normalized elution profiles obtained after loading on the column 10 (dotted), 30 (dash-dotted), 60 (dashed) and 120 (solid) $\mu \mathrm{g}$ dissolved in $100 \mu \mathrm{L}$ of buffer are presented. (C) Sedimentation velocity analysis of the wild type HspB1 (1) and its R27A mutant (2).

Table 1. Apparent molecular weight and estimated number of subunits in oligomers of different small heat shock proteins determined by size-exclusion chromatography (SEC) and SEC-SAXS.

\begin{tabular}{cccc}
\hline Protein & Monomeric Mass, kDa & $\begin{array}{c}\text { Apparent Mass/ } \\
\text { No. of Monomers WT }\end{array}$ & $\begin{array}{c}\text { Apparent Mass/ } \\
\text { No. of Monomers Mutant }\end{array}$ \\
\hline HspB1 & 22.8 & $540 / \sim 24$ & $500 / \sim 22+80 / \sim 4 *$ \\
HspB4 & 19.9 & $590 / \sim 30$ & $590 / \sim 30$ \\
HspB5 & 20.2 & $540 / \sim 27$ & $460 / \sim 23$ \\
HspB6 & 17.1 & $50 / \sim 3^{* *}$ & $50 / \sim 3$ \\
HspB8 & 21.6 & $33 / \sim 2^{* * *}$ & $60 / \sim 3$ \\
\hline
\end{tabular}

* smaller species at low concentration; ** predominantly a dimer $[33,34] ;{ }^{* * *}$ predominantly a dimer according to SEC-SAXS measurements (this work).

The SEC profiles indicate that the wild type HspB5 formed large stable oligomers with apparent molecular weight of $\sim 540 \mathrm{kDa}$ similar to those formed by the wild type HspB1 and slightly smaller than those formed by HspB4 (Figure 6). The R22A mutant of HspB5 also formed stable oligomers with a slightly lower apparent molecular weight of $\sim 460 \mathrm{kDa}$. In both cases, the size of oligomers was independent of protein concentration loaded on the column (Figure 6). Two peaks were detected on the sedimentogram of the wild type HspB5 and its point mutant. The first small peak with sedimentation coefficient of 3.0-3.5 S probably corresponds to small oligomers (probably crystalline tetramers). The second peak with sedimentation coefficient $\sim 16 \mathrm{~S}$ for the wild type HspB5 and sedimentation coefficient $\sim 14 \mathrm{~S}$ for R22A mutant of HspB5 correspond to the large oligomers of these proteins (Figure 6). The hydrodynamic diameter determined by DLS was equal to $11.8 \pm 0.6 \mathrm{~nm}(n=150)$ for the wild type protein and $11.1 \pm 0.4 \mathrm{~nm}(n=130)$ for its R22A mutant. 

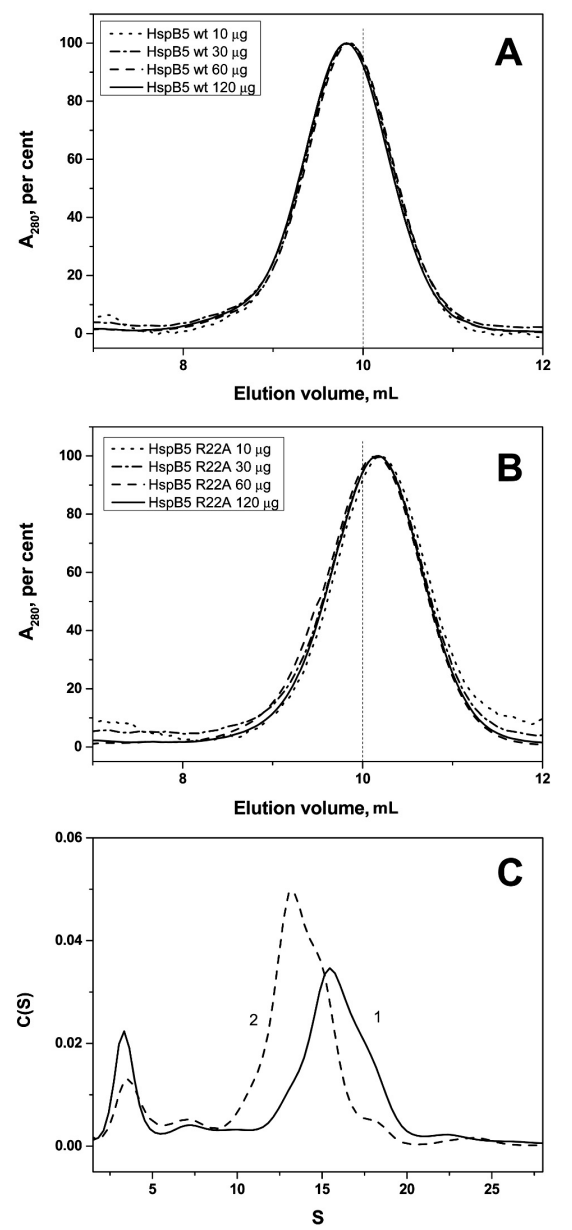

Figure 6. Effect of R22A mutation on quaternary structure of HspB5. Size-exclusion chromatography of the wild type HspB5 (A) and its R22A mutant (B) Normalized elution profiles obtained after loading on the column 10 (dotted), 30 (dash-dotted), 60 (dashed) and 120 (solid) $\mu \mathrm{g}$ dissolved in $100 \mu \mathrm{L}$ of buffer are presented. (C) Sedimentation velocity analysis of the wild type HspB5 (1) and its R22A mutant (2).

Human wild type HspB6 formed only small size oligomers with an apparent molecular weight of $\sim 50 \mathrm{kDa}$ on SEC (Supplementary Material Figure S4). An increase in the concentration of loaded sample was accompanied by minimal changes of the apparent molecular weight. Similar results were obtained with the R27A mutant of HspB6 (Supplementary Material Figure S4). Both the wild type HspB6 and its R27A mutant had a similar sedimentation coefficient $\sim 2.5-3.0 \mathrm{~S}$, and their hydrodynamic diameter was equal $5.9 \pm 0.8 \mathrm{~nm}(n=130)$.

Like HSPB6, the wild type HspB8 also formed small oligomers with an apparent molecular weight of $33 \mathrm{kDa}$ on SEC (Figure 7). The elution volume of wild type HspB8 was only weakly dependent on the quantity of protein loaded on the column. At the same time the R29A mutant of HspB8 eluted with an apparent molecular weight of $\sim 60 \mathrm{kDa}$ and its elution volume was again independent of the quantity of protein loaded on the column (Figure 7). The smallest oligomer formed by the wild type HSPB8 was previously suggested to be a dimer [35]. Since the obtained SEC-based apparent mass value was significantly deviating from that of the expected dimer, we additionally performed an online SEC-SAXS experiment using synchrotron radiation (Supplementary Material Figure S5). When $230 \mu \mathrm{M}$ of sample was applied, the separation on the SEC column resulted in one major peak. The resulting SAXS curve, and corresponding dimensionless-Kratky and pair-distribution plots suggest that the protein contains a core folded region with extended disordered regions similar to what was previously reported for HspB6 [33]. Mass estimates at the elution peak center resulted in a value of $49 \mathrm{kDa}$ using the volume of correlation invariant [36]. Hence, we conclude that the main species of the wild type 
HspB8 in a moderately concentrated solution is a dimer, whereas the mutation causes an approximate doubling of the mass, i.e., a tetramer. These unexpected results were confirmed by AUC where the sedimentation coefficient of the wild type HspB8 was determined to be equal to $2.5 \mathrm{~S}$, whereas the R29A mutant was sedimented with a coefficient of $5.8 \mathrm{~S}$ (Figure 7). These data also agree with results obtained by DLS indicating that the hydrodynamic diameter of the wild type HspB8 is equal to $5.6 \pm 0.4 \mathrm{~nm}(n=130)$, whereas the hydrodynamic diameter of its R29A mutant is equal to $6.2 \pm 0.4 \mathrm{~nm}$ $(n=130)$.
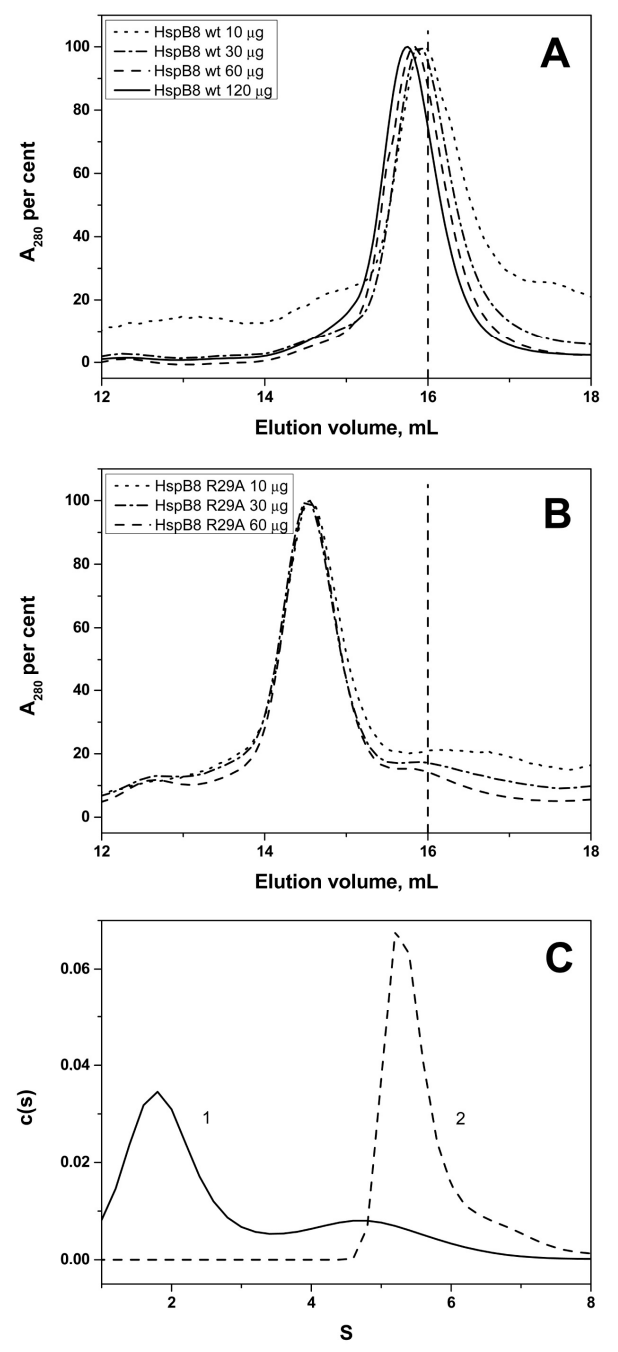

Figure 7. Effect of R29A mutation on quaternary structure of HspB8. Size-exclusion chromatography of the wild type HspB8 (A) and its R29A mutant (B) Normalized elution profiles obtained after loading on the column 10 (dotted), 30 (dash-dotted), 60 (dashed) and 120 (solid) $\mu \mathrm{g}$ dissolved in $100 \mu \mathrm{L}$ of buffer are presented. (C) Sedimentation velocity analysis of the wild type HspB8 (1) and its R29A mutant (2).

The changes in the quaternary structure of $\mathrm{HspB} 8$ upon mutation could be further confirmed using chemical cross-linking. Incubation with DSS was accompanied by accumulation of both intramonomer and intermonomer cross-linked proteins (Figure 8). Cross-linking of the wild type protein resulted in accumulation of very diffuse bands corresponding to cross-linked monomers (apparent molecular weight $22 \mathrm{kDa}$ ) and dimers (apparent molecular weight $\sim 45 \mathrm{kDa}$ ) (Figure $8 \mathrm{~A}$ ). At the same time cross-linking of the R29A mutant resulted in accumulation of cross-linked monomer (apparent molecular weight $22 \mathrm{kDa}$ ) as well as cross-linked dimers (apparent molecular weight $\sim 45 \mathrm{kDa}$ ) and cross-linked oligomers with high apparent molecular weight (about $116 \mathrm{kDa}$ ) that were absent in the 
case of the wild type protein (Figure 8B). Qualitatively similar results were obtained when HspB8 and its mutant were subjected to mild oxidation of SH groups (data not presented).

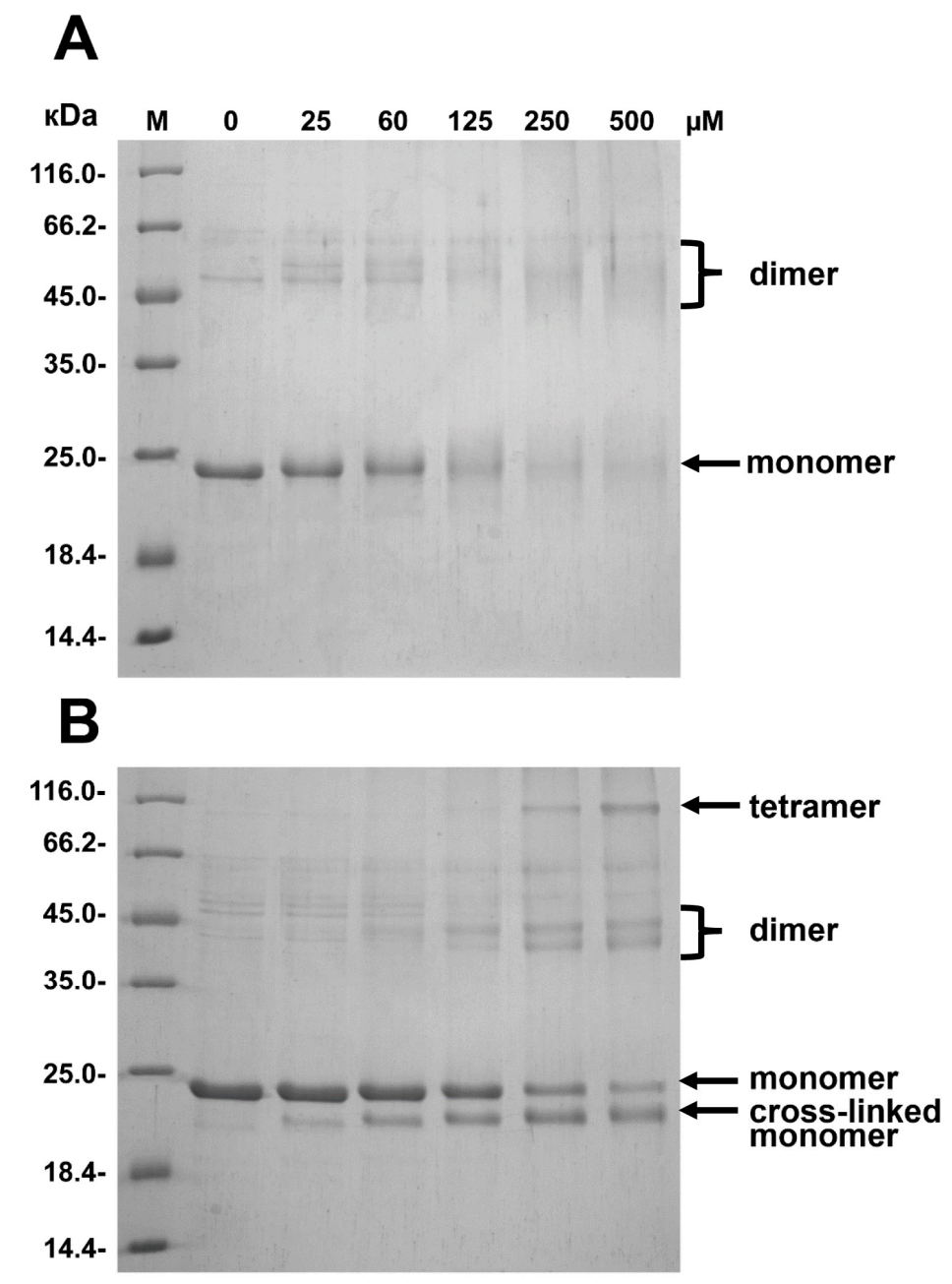

Figure 8. Chemical crosslinking of the wild type HspB8 (A) and its R29A mutant (B) by DSS. The wild type HspB8 and its R29A mutant $(1.3 \mathrm{mg} / \mathrm{mL})$ were incubated for $30 \mathrm{~min}$ in PBS with different concentrations of DSS (indicated above each track). Molecular weight markers were loaded on track labeled M.

\subsection{Lack of the Effect of Arg/Ala Replacement on Chaperone-Like Activity}

Heating of apo-ovotransferrin leads to its denaturation and aggregation (Figure 9). HspB1, HspB4, HspB5, and HspB6 inhibited ovotransferrin aggregation and chaperone-like activity of the wild type proteins was comparable with that of the corresponding R to A mutants (Figure 9). Only in the case of HspB4 was the wild type protein slightly more effective than its corresponding R21A mutant. At the same time, HspB8 and its R29A mutant were unable to inhibit ovotransferrin aggregation and instead slightly increased aggregation of this model substrate (Figure 9E). 

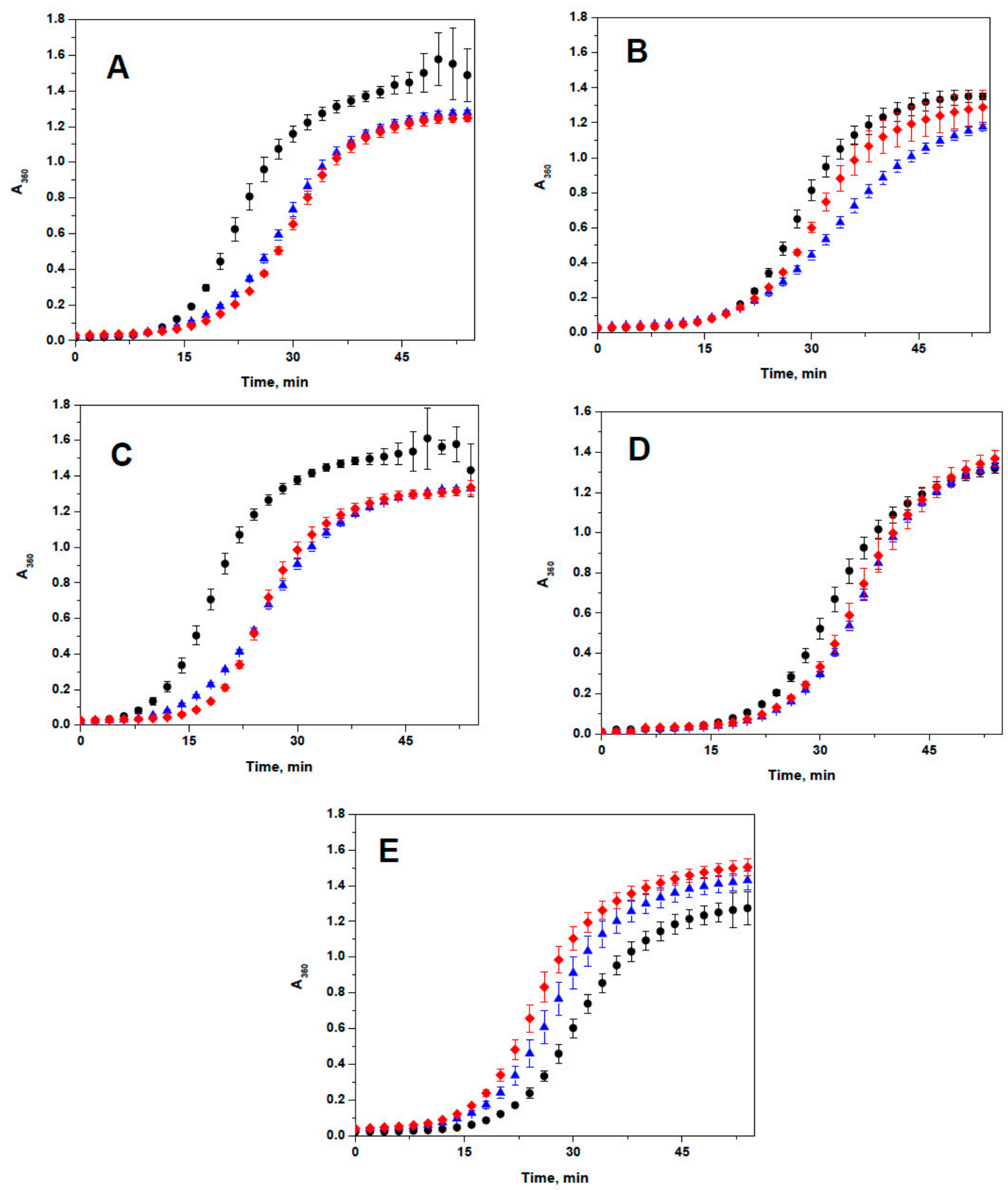

Figure 9. Chaperone-like activity of HspB1 (A), HspB4 (B), HspB5 (C), HspB6 (D) and HspB8 (E) with ovotransferrin as a model substrate. Kinetics of aggregation of isolated ovotransferrin (black circles) and ovotransferrin in the presence of the wild type protein (blue triangles) or aggregation of ovotransferrin in the presence of corresponding R/A mutant (red diamonds) were recorded in no less than three independent experiments and data presented are mean with error bars corresponding to standard deviation. Weight ratio ovotransferrin/sHsp was equal to 50 for HspB1, 11 for HspB4, 17 for HspB5, 14 HspB6, and 15 for HspB8.

Similar results were obtained when another model substrate, myosin subfragment- 1 , was used for estimation of chaperone-like activity. Again HspB1, HspB4, HspB5, and HspB6 demonstrated chaperone-like activity and this activity was comparable for both the wild type protein and its Arg/Ala mutants. HspB8 and its point mutant did not inhibit heat-induced aggregation of S-1 fragment of myosin and even slightly increased its aggregation demonstrating anti-chaperone activity (Supplementary Material Figure S6). 


\section{Discussion}

Human sHsps are known to have major differences in their ability to form large oligomers. In particular, HspB1, HspB4, and HspB5 form species with an apparent molecular weight of more than $500 \mathrm{kDa}$, while HspB2 and HspB3 form hetero-tetramers, and HspB6 and HspB8 form smaller entities. The tendency to form large oligomers is known to correlate with the presence of a conserved IXI motif in the CTD $[7,8,37]$. Of the five proteins studied here, this is only the case in HspB1, HspB4, and HspB5. Although this motif plays an important role in the interaction of sHsp dimers within the large oligomers, stability of these large oligomers appears to be mostly dependent on the structure and properties of their respective NTDs. The detailed location of the NTD within the oligomeric assembly is a subject of a debate, but it is likely that the NTDs are buried in the core of the oligomer. Interacting with each other and probably with the ACDs, the NTDs stabilize the overall structure of these oligomers [16,38,39]. Indeed, point mutations [40] and posttranslational modifications $[12,16,41]$ affect the oligomeric structure of HspB1 and HspB5. Specifically, removal of the overall positive charge in the NTD often leads to the dissociation of large sHsp oligomers, as evident from the data on phosphorylation and phosphomimicking mutations of Ser15, Ser78, and Ser82 in HspB1, and Ser19, Ser 45, and Ser79 in HspB5 [12,16]. On the flip side, introduction of excessive positive charges as a rule prevents or decreases dissociation induced by phosphorylation. For instance, G34R and E41K mutants of HspB1 are much more resistant to phosphorylation-induced dissociation than the wild type protein [29], and replacement of certain negatively charged residues by cysteine in the NTD of a triple serine to aspartate mutant of HspB1 yielded large oligomers [40].

We demonstrate here that the replacement R/A in the conserved RLFDQxFG motif of HspB1 and HspB5, i.e., decrease of positive charge in the NTD, provokes destabilization of large oligomers of HspB1 (Figure 5) and decreases the size of large oligomers of HspB5 (Figure 6). HspB4 forms a heterogeneous mixture of different oligomers (Supplementary Material Figure S3), and therefore it was difficult to follow the changes induced by the R21A mutation to its structure. At the same time it is worthwhile mentioning that mutations R21L, R21W, or R21Q in HspB4 are associated with cataract [42-46], suggesting that a mutation of residue R21 could affect the interaction of HspB4 with HspB5.

Both HspB6 and HspB8 lack the IP(V/I) motif in the CTD and are known to have a much reduced tendency to form large oligomers compared to other human sHsps [33,34,47]. We show that the R27A mutation induced only small changes in the optical properties or oligomeric structure of HspB6 (Supplementary Material Figures S1 and S2). These results agree with the earlier published data indicating that the point mutations Q31A and Q31L have only a moderate effect on the quaternary structure of HspB6 [24] and that phosphorylation (or phosphomimicking mutation) of Ser16 affects the quaternary structure of HspB6 only under crowding conditions [48,49]. Although the R27A mutation described in this work and the larger deletion of residues $21-30$ or 31-40 do not significantly affect oligomeric structure of isolated HspB6 [24], the conserved motif RLFDQxFG seems to play crucial role in formation of heterooligomeric complexes of HspB6 and HspB1 [27].

Through a combination of biophysical methods, including SEC-SAXS experiments, we could demonstrate that at moderate concentrations HspB8 is predominantly present as dimers in solution, which is in line with earlier data $[35,50]$. Proteomics investigations indicate that this protein can be phosphorylated at Ser24 and Thr/Ser87 by different protein kinases in vivo [17,51]. Phosphorylation or phosphomimicking mutations of Ser24, Ser27, and Thr87 are accompanied by changes of Trp fluorescence, susceptibility to limited proteolysis, and an increase in the apparent molecular weight of HspB8 [52]. This means that in the case of HspB8 introduction of negative charges induces large changes in the structure and/or orientation of the NTD. Here we show that the replacement of positively charged Arg by Ala results in a significant increase in the apparent molecular weight and sedimentation coefficient (Figure 7). Cross-linking experiments indicate that R29A mutation was accompanied by the accumulation of large oligomers with apparent molecular weight of more than $116 \mathrm{kDa}$ that were not observed for the wild type protein (Figure 8). It seems likely that this mutation 
in HspB8 stabilizes the structure of the intrinsically disordered NTD, which promotes the association of dimers into tetrameric species.

Finally, analysis of chaperone-like activity has not revealed dramatic changes induced by replacement of conserved Arg (Figure 9). However, depending on substrate nature, all five sHsp demonstrated different chaperone (or antichaperone in the case of HspB8) activity. In this respect our results correlate with the recently published data of Mymrikov et al. [53].

Phylogenetic analysis indicates that the five sHsps belong to two different clades (Figure 1B) [18,54]. HspB1 and HspB8 are closely related and belong to one clade, whereas HspB4, HspB5, and HspB6 belong to another clade. The main difference between these two clades is a rather large insert at the end of the N-terminal domain (residues 59-73 of HspB1 and residues 62-75 of HspB8) which is only present in the first clade. This insert (marked as P1) is poorly conserved and rich in Pro. This part of the NTD was hypothesized to play a role in the formation of large HspB1 oligomers [55]. Of note, the replacement of Arg by Ala in the conserved RLFDQxFG motif was accompanied by pronounced changes in spectral properties and/or temperature-induced aggregation only in the sHsp belonging to the first clade (HspB1 and HspB8). In HspB1, this replacement has apparently lead to some destabilization of the HspB1 oligomers (Figure 5). However, the mutation had an opposite effect in normally dimeric HspB8, inducing the formation of tetramers. It seems surprising that the single point mutation induces significant changes in the oligomeric state of HspB8. In this respect, it is worthwhile to mention that highly homologous human and rat HspB6 containing only a few substitutions in the NTD differ in their ability to form oligomers. Indeed, rat HspB6 tends to form concentration-dependent oligomers [56], whereas human HspB6 is predominantly presented by dimers $[33,49]$. Thus our data indicate that the effect of the conserved RLFDQxFG motif on the oligomeric structure depends on the context of the particular sHsp.

\section{Materials and Methods}

\subsection{Proteins}

A pET23b construct containing the human HspB1, HspB4, HspB5, HspB6, and HspB8 sequences were used by Eurogen (Moscow, Russia) for generating expression constructs encoding R27A HspB1, R21A HspB4, R22A HspB5, R27A HspB6, and R29A HspB8 mutants. The integrity of each construct was confirmed by sequencing. All proteins were expressed in the BL21(DE3)pLysS E. coli strain by culturing either in LB at $37^{\circ} \mathrm{C}$ and inducing production with $0.5 \mathrm{mM}$ IPTG (HspB1, HspB4, HspB5, HspB8) or by using auto-induction media at the same temperature (HspB6) [57]. Earlier described methods were used for purification of the wild type proteins and their mutants [49,58]. Briefly, the bacterial lysate was subjected to ammonium sulfate fractionation, followed by ion-exchange chromatography on HiTrap Q HP (in the case of HspB1, HspB4, and HspB5) or hydrophobic chromatography on HiTrap Phenyl Sepharose (in the case of HspB6 and HspB8). Finally all proteins were subjected to size-exclusion chromatography (SEC) using a Superdex-200 (GE Healthcare, Uppsala, Sweden). According to SDS-PAGE analysis [59], the purity of all protein samples was higher than $95 \%$. All proteins were aliquoted and stored at $-20^{\circ} \mathrm{C}$ in buffer $\mathrm{B}(20 \mathrm{mM}$ Tris/acetate $\mathrm{pH} 7.6$ containing $10 \mathrm{mM} \mathrm{NaCl}, 0.1 \mathrm{mM}$ EDTA, $0.1 \mathrm{mM}$ PMSF and $2 \mathrm{mM}$ DTT).

\subsection{Fluorescence Spectroscopy and Light Scattering}

Fluorescence of all proteins $(0.05-0.15 \mathrm{mg} / \mathrm{mL})$ was measured at $25^{\circ} \mathrm{C}$ in buffer $\mathrm{F}$ containing $20 \mathrm{mM}$ HEPES/NaOH pH 7.6, $100 \mathrm{mM} \mathrm{NaCl}, 0.5 \mathrm{mM}$ EDTA, and $2 \mathrm{mM}$ DTT. Fluorescence was excited at $295 \mathrm{~nm}$ (slit width $5 \mathrm{~nm}$ ) and recorded in the range of 310-400 nm (slit width $5 \mathrm{~nm}$ ).

Heat-induced aggregation was monitored by heating of protein samples $(0.3 \mathrm{mg} / \mathrm{mL})$ in buffer $\mathrm{F}$ with a constant rate of $1{ }^{\circ} \mathrm{C} / \mathrm{min}$ from 25 to $90^{\circ} \mathrm{C}$. The samples were illuminated at $340 \mathrm{~nm}$ (slit width $2.5 \mathrm{~nm}$ ) and signal was recorded at $340 \mathrm{~nm}$ (slit with $2.5 \mathrm{~nm}$ ). All fluorescent and static light scattering 
experiments were performed on a Varian Carry Eclipse spectrofluorometer (Agilent, Santa Clara, CA, USA).

Dynamic light scattering was performed on Zetasizer Nano ZS (Malvern Panalytical, Malvern, UK). All protein solutions were prepared in buffer F filtered through $0.2 \mu \mathrm{m}$ filter. Experiments were performed at $25{ }^{\circ} \mathrm{C}$ at protein concentration equal to $0.3 \mathrm{mg} / \mathrm{mL}$ for HspB1, HspB5, and HspB4 and at concentration equal to $0.6 \mathrm{mg} / \mathrm{mL}$ for HspB6 and HspB8. Each experiment lasted for $10 \mathrm{~s}$ and was repeated 15 times. This cycle was repeated 10 times, thus providing the accumulation of 150 measurements. Number distribution was used for calculation of hydrodynamic diameter with Zetasizer software.

\subsection{Size-Exclusion Chromatography}

The quaternary structure was analyzed by means of size-exclusion chromatography (SEC) performed on a Superdex $200 \mathrm{HR} 10 / 30$ column equilibrated with buffer containing $20 \mathrm{mM}$ Tris/acetate (pH 7.6), $150 \mathrm{mM} \mathrm{NaCl}, 0.1 \mathrm{mM}$ EDTA, $0.1 \mathrm{mM}$ PMSF, and $15 \mathrm{mM} \beta$-mercaptoethanol. Samples containing 10-120 $\mu \mathrm{g}$ of protein dissolved in $100 \mu \mathrm{L}$ of the same buffer were loaded on the column and eluted with the rate $0.5 \mathrm{~mL} / \mathrm{min}$. The column was calibrated with thyroglobulin $(660 \mathrm{kDa})$, ferritin (440 kDa), aldolase (158 kDa), conalbumin (75 kDa), ovalbumin (43 kDa), carboanhydrase (29 kDa), and RNAse (13.7 kDa).

\subsection{Analytical Ultracentrifugation}

The wild type proteins and their point mutants at equal concentration $(0.4 \mathrm{mg} / \mathrm{mL}$ for HspB1 and HspB8 and $0.8 \mathrm{mg} / \mathrm{mL}$ for HspB4, HspB5, and HspB6) were diluted and dialyzed against $50 \mathrm{mM}$ phosphate buffer ( $\mathrm{pH}$ 6.8), containing $150 \mathrm{mM} \mathrm{NaCl}$ and $2 \mathrm{mM}$ DTT. The samples were subjected to ultracentrufugation $(42,000 \mathrm{rpm})$ in a Spinco $\mathrm{E}$ analytical ultracentrifuge at $20^{\circ} \mathrm{C}$ in a six-hole AnJ-Ti rotor and $12 \mathrm{~mm}$ double sector cells. All cells were scanned at $280 \mathrm{~nm}$ with a 3 min interval between measurements. Sedimentation coefficients were estimated from differential distribution of sedimentation coefficients $\left[\mathrm{c}\left(\mathrm{s}, \mathrm{f} / \mathrm{f}_{\mathrm{o}}\right)\right.$ vs. $\left.\mathrm{s}\right]$ using SEDFIT program [60].

\subsection{SEC-SAXS Studies}

SAXS experiments were performed on the SWING beamline at the Synchrotron Soleil [61] essentially as described before [24]. Briefly, a $75 \mathrm{~mL}$ sample of wild-type $\mathrm{HspB} 8$ at $5 \mathrm{mg} / \mathrm{mL}$ was loaded onto a Shodex KW404-4F pre-equilibrated in $20 \mathrm{mM}$ HEPES, $150 \mathrm{mM} \mathrm{NaCl}, \mathrm{pH}$ 7.4, and $2.5 \mathrm{mM}$ DTT. Scattering data of the column eluent was collected using a $0.75 \mathrm{~s}$ exposure, with a $1 \mathrm{~s}$ delay between frames. Initial data reduction was performed using FOXTROT (available at the SWING beamline, https://www.synchrotron-soleil.fr/en/beamlines/swing) and processed further using ScÅtter (available online: http://www.bioisis.net/tutorial), the output of the processed data is presented in Supplementary Material Figure S5.

\subsection{Crosslinking of $\mathrm{HspB8}$}

Two approaches were used for cross-linking of HspB8 and its mutant. Firstly, disulfide bridge formation was examined. The sample was subjected to centrifugation $(12,000 \times g, 15 \mathrm{~min})$. The concentrations of the wild type proteins and its mutant were equalized $(1.2 \mathrm{mg} / \mathrm{mL})$ and both samples were dialyzed against buffer B ( $20 \mathrm{mM}$ Tris/acetate $\mathrm{pH}$ 7.6, $10 \mathrm{~mm} \mathrm{NaCl}, 0.1 \mathrm{mM}$ EDTA, and $0.1 \mathrm{mM} \mathrm{PMSF}$ ) at $37^{\circ} \mathrm{C}$ for different amounts of time lasting from 2 up to $24 \mathrm{~h}$. HspB8 contains 3 Cys residues and mild oxidation leads to formation of both cross-linked monomers and cross-linked oligomers [35]. The reaction was stopped by the addition of an excess of iodoacetamide. The oligomeric state of the samples thus obtained was analyzed by SDS-gel electrophoresis [59].

Secondly, HspB8 and its mutant were cross-linked by suberic acid bis( $N$-hydroxysuccinimide ester) (DSS). The samples of wild type HspB8 and its mutant were reduced by addition of $5 \mathrm{mM}$ DTT and incubated for $10 \mathrm{~min}$ at $37^{\circ} \mathrm{C}$. The protein samples were desalted and transferred to PBS by using 
Zeba Micro Spin Desalting Columns. The protein concentration was equalized $(1.6 \mathrm{mg} / \mathrm{mL})$ and both proteins were incubated in PBS for $30 \mathrm{~min}$ at $37^{\circ} \mathrm{C}$ with DSS concentration equal to $0,25,60,125,250$, and $500 \mu \mathrm{M}$. The reaction was stopped by the addition of Tris, up to the final concentration of $20 \mathrm{mM}$, and afterwards subjected to SDS-PAGE analysis [59].

\subsection{Chaperone-Like Activity}

Two model protein substrates, chicken apo-ovotransferrin and subfragment-1 of rabbit skeletal muscle myosin, were used for determination of chaperone-like activity. Chicken ovotransferrin was purified as described earlier [62] and its apoform was prepared according to Evans and Holbrook [63]. All experiments were performed in $50 \mathrm{mM}$ phosphate $\mathrm{pH}$ 7.4, containing $100 \mathrm{mM} \mathrm{NaCl}$ and $20 \mathrm{mM}$ DTT at $45{ }^{\circ} \mathrm{C}$. Small heat shock proteins (final concentration $0.010-0.045 \mathrm{mg} / \mathrm{mL}$ ) were preincubated in reaction mixture for $8 \mathrm{~min}$ and the reaction was started by addition of apo-ovotransferrin (final concentration $0.5 \mathrm{mg} / \mathrm{mL}$ ). Kinetics of ovotransferrin aggregation was followed by measuring optical density at $360 \mathrm{~nm}$ on an Ultrospec 3100 spectrophotometer (GE Healthcare, Uppsala, Sweden). All experiments were repeated no less than three times and results presented are mean $\pm \mathrm{SD}$.

Subfragment-1 of rabbit skeletal myosin was obtained as described earlier [64] and was kindly provided by Professor D.I. Levitsky (Institute of Biochemistry, Russian Academy of Sciences). All experiments were performed in $20 \mathrm{mM} \mathrm{HEPES} / \mathrm{NaOH}$ pH 7.0, $115 \mathrm{mM} \mathrm{KCl}$, and $20 \mathrm{mM}$ DTT at $42{ }^{\circ} \mathrm{C}$. Small heat shock proteins were incubated in the abovementioned buffer for $8 \mathrm{~min}$ in order to reduce all sulfhydryl groups and the reaction was started by addition of subfragment-1 (S1) up to the final concentration of $0.4 \mathrm{mg} / \mathrm{mL}$. Aggregation of S1 was followed by measuring optical density at $340 \mathrm{~nm}$ in the absence or in the presence $(0.02-0.04 \mathrm{mg} / \mathrm{mL})$ of different small heat shock proteins. All experiments were repeated no less than three times and results presented are mean \pm SD.

Supplementary Materials: Supplementary materials can be found at http:/ /www.mdpi.com/1422-0067/19/7/ 2112/s1.

Author Contributions: N.B.G., S.V.S., and S.D.W. conceived and designed the experiments. V.M.S. and S.D.W. conducted most of experiments. N.B.G., S.V.S., and S.D.W. prepared and edited manuscript. S.V.S. and N.B.G. provided funding acquisition.

Funding: This investigation was supported by the Russian Science Foundation (grant No. 14-35-00026) and Russian Foundation for Basic Science (grants No. 16-04-00016) to NBG. This work was further supported by the Research Foundation Flanders (FWO) grants G093615N and WO03315N (to SVS). We acknowledge support from the European Community's Seventh Framework Programme under the BioStruct-X initiative (Project Number 6131) for SAXS measurements on the SWING beamline (Soleil synchrotron, Saint-Aubin, France).

Conflicts of Interest: The authors declare no conflict of interest.

\section{References}

1. Kriehuber, T.; Rattei, T.; Weinmaier, T.; Bepperling, A.; Haslbeck, M.; Buchner, J. Independent evolution of the core domain and its flanking sequences in small heat shock proteins. FASEB J. 2010, 24, 3633-3642. [CrossRef] [PubMed]

2. Maaroufi, H.; Tanguay, R.M. Analysis and phylogeny of small heat shock proteins from marine viruses and their cyanobacteria host. PLoS ONE 2013, 8, e81207. [CrossRef] [PubMed]

3. Slingsby, C.; Wistow, G.J. Functions of crystallins in and out of lens: Roles in elongated and post-mitotic cells. Prog. Biophys. Mol. Biol. 2014, 115, 52-67. [CrossRef] [PubMed]

4. Bakthisaran, R.; Tangirala, R.; Rao, C.M. Small heat shock proteins: Role in cellular functions and pathology. Biochim. Biophys. Acta 2015, 1854, 291-319. [CrossRef] [PubMed]

5. Treweek, T.M.; Meehan, S.; Ecroyd, H.; Carver, J.A. Small heat-shock proteins: Important players in regulating cellular proteostasis. Cell. Mol. Life Sci. 2015, 72, 429-451. [CrossRef] [PubMed]

6. Poulain, P.; Gelly, J.C.; Flatters, D. Detection and architecture of small heat shock protein monomers. PLoS ONE 2010, 5, e9990. [CrossRef] [PubMed]

7. Hochberg, G.K.; Benesch, J.L. Dynamical structure of $\alpha$ b-crystallin. Prog. Biophys. Mol. Biol. 2014, 115, 11-20. [CrossRef] [PubMed] 
8. Delbecq, S.P.; Rosenbaum, J.C.; Klevit, R.E. A mechanism of subunit recruitment in human small heat shock protein oligomers. Biochemistry 2015, 54, 4276-4284. [CrossRef] [PubMed]

9. Haslbeck, M.; Peschek, J.; Buchner, J.; Weinkauf, S. Structure and function of $\alpha$-crystallins: Traversing from in vitro to in vivo. Biochim. Biophys. Acta 2016, 1860, 149-166. [CrossRef] [PubMed]

10. Sobott, F.; Benesch, J.L.; Vierling, E.; Robinson, C.V. Subunit exchange of multimeric protein complexes. Real-time monitoring of subunit exchange between small heat shock proteins by using electrospray mass spectrometry. J. Biol. Chem. 2002, 277, 38921-38929. [CrossRef] [PubMed]

11. Benesch, J.L.; Ayoub, M.; Robinson, C.V.; Aquilina, J.A. Small heat shock protein activity is regulated by variable oligomeric substructure. J. Biol. Chem. 2008, 283, 28513-28517. [CrossRef] [PubMed]

12. Jovcevski, B.; Kelly, M.A.; Rote, A.P.; Berg, T.; Gastall, H.Y.; Benesch, J.L.; Aquilina, J.A.; Ecroyd, H. Phosphomimics destabilize hsp27 oligomeric assemblies and enhance chaperone activity. Chem. Biol. 2015, 22, 186-195. [CrossRef] [PubMed]

13. Benndorf, R.; Hayess, K.; Ryazantsev, S.; Wieske, M.; Behlke, J.; Lutsch, G. Phosphorylation and supramolecular organization of murine small heat shock protein hsp25 abolish its actin polymerization-inhibiting activity. J. Biol. Chem. 1994, 269, 20780-20784. [PubMed]

14. Aquilina, J.A.; Watt, S.J. The N-terminal domain of $\alpha$ b-crystallin is protected from proteolysis by bound substrate. Biochem. Biophys. Res. Commun. 2007, 353, 1115-1120. [CrossRef] [PubMed]

15. Mymrikov, E.V.; Seit-Nebi, A.S.; Gusev, N.B. Large potentials of small heat shock proteins. Physiol. Rev. 2011, 91, 1123-1159. [CrossRef] [PubMed]

16. Peschek, J.; Braun, N.; Rohrberg, J.; Back, K.C.; Kriehuber, T.; Kastenmuller, A.; Weinkauf, S.; Buchner, J. Regulated structural transitions unleash the chaperone activity of $\alpha$ b-crystallin. Proc. Natl. Acad. Sci. USA 2013, 110, E3780-E3789. [CrossRef] [PubMed]

17. Dephoure, N.; Zhou, C.; Villen, J.; Beausoleil, S.A.; Bakalarski, C.E.; Elledge, S.J.; Gygi, S.P. A quantitative atlas of mitotic phosphorylation. Proc. Natl. Acad. Sci. USA 2008, 105, 10762-10767. [CrossRef] [PubMed]

18. Heirbaut, M.; Strelkov, S.V.; Weeks, S.D. Everything but the ACD, Functional Conservation of the Non-conserved Terminal Regions in sHSPs. In The Big Book on Small Heat Shock Proteins; Tanguay, R.M., Hightower, L.E., Eds.; Springer International Publishing: Basel, Switzerland, 2015; pp. 197-227.

19. Sudnitsyna, M.V.; Mymrikov, E.V.; Seit-Nebi, A.S.; Gusev, N.B. The role of intrinsically disordered regions in the structure and functioning of small heat shock proteins. Curr. Protein Pept. Sci. 2012, 13, 76-85. [CrossRef] [PubMed]

20. Hanazono, Y.; Takeda, K.; Oka, T.; Abe, T.; Tomonari, T.; Akiyama, N.; Aikawa, Y.; Yohda, M.; Miki, K. Nonequivalence observed for the 16-meric structure of a small heat shock protein, sphsp16.0, from schizosaccharomyces pombe. Structure 2013, 21, 220-228. [CrossRef] [PubMed]

21. Van Montfort, R.L.; Basha, E.; Friedrich, K.L.; Slingsby, C.; Vierling, E. Crystal structure and assembly of a eukaryotic small heat shock protein. Nat. Struct. Biol. 2001, 8, 1025-1030. [CrossRef] [PubMed]

22. Merck, K.B.; De Haard-Hoekman, W.A.; Oude Essink, B.B.; Bloemendal, H.; De Jong, W.W. Expression and aggregation of recombinant $\alpha$ a-crystallin and its two domains. Biochim. Biophys. Acta 1992, 1130, 267-276. [CrossRef]

23. Bova, M.P.; McHaourab, H.S.; Han, Y.; Fung, B.K. Subunit exchange of small heat shock proteins. Analysis of oligomer formation of $\alpha$ a-crystallin and hsp27 by fluorescence resonance energy transfer and site-directed truncations. J. Biol. Chem. 2000, 275, 1035-1042. [CrossRef] [PubMed]

24. Heirbaut, M.; Beelen, S.; Strelkov, S.V.; Weeks, S.D. Dissecting the functional role of the N-terminal domain of the human small heat shock protein hspb6. PLoS ONE 2014, 9, e105892. [CrossRef] [PubMed]

25. Pasta, S.Y.; Raman, B.; Ramakrishna, T.; Rao Ch, M. Role of the conserved srlfdqffg region of $\alpha$-crystallin, a small heat shock protein. Effect on oligomeric size, subunit exchange, and chaperone-like activity. J. Biol. Chem. 2003, 278, 51159-51166. [CrossRef] [PubMed]

26. Kumar, L.V.; Rao, C.M. Domain swapping in human $\alpha$ a and $\alpha$ b crystallins affects oligomerization and enhances chaperone-like activity. J. Biol. Chem. 2000, 275, 22009-22013. [CrossRef] [PubMed]

27. Heirbaut, M.; Lermyte, F.; Martin, E.M.; Beelen, S.; Sobott, F.; Strelkov, S.V.; Weeks, S.D. Specific sequences in the n-terminal domain of human small heat-shock protein hspb6 dictate preferential hetero-oligomerization with the orthologue hspb1. J. Biol. Chem. 2017, 292, 9944-9957. [CrossRef] [PubMed]

28. Santhoshkumar, P.; Sharma, K.K. Phe71 is essential for chaperone-like function in $\alpha$ a-crystallin. J. Biol. Chem. 2001, 276, 47094-47099. [CrossRef] [PubMed] 
29. Muranova, L.K.; Weeks, S.D.; Strelkov, S.V.; Gusev, N.B. Characterization of mutants of human small heat shock protein hspb1 carrying replacements in the n-terminal domain and associated with hereditary motor neuron diseases. PLoS ONE 2015, 10, e0126248. [CrossRef] [PubMed]

30. Irobi, J.; Van Impe, K.; Seeman, P.; Jordanova, A.; Dierick, I.; Verpoorten, N.; Michalik, A.; De Vriendt, E.; Jacobs, A.; Van Gerwen, V.; et al. Hot-spot residue in small heat-shock protein 22 causes distal motor neuropathy. Nat. Genet. 2004, 36, 597-601. [CrossRef] [PubMed]

31. Ghaoui, R.; Palmio, J.; Brewer, J.; Lek, M.; Needham, M.; Evila, A.; Hackman, P.; Jonson, P.H.; Penttila, S.; Vihola, A.; et al. Mutations in hspb8 causing a new phenotype of distal myopathy and motor neuropathy. Neurology 2016, 86, 391-398. [CrossRef] [PubMed]

32. Li, F.; Xiao, H.; Hu, Z.; Zhou, F.; Yang, B. Exploring the multifaceted roles of heat shock protein b8 (hspb8) in diseases. Eur. J. Cell Biol. 2018, 97, 216-229. [CrossRef] [PubMed]

33. Weeks, S.D.; Baranova, E.V.; Heirbaut, M.; Beelen, S.; Shkumatov, A.V.; Gusev, N.B.; Strelkov, S.V. Molecular structure and dynamics of the dimeric human small heat shock protein hspb6. J. Struct. Biol. 2014, 185, 342-354. [CrossRef] [PubMed]

34. Heirbaut, M.; Lermyte, F.; Martin, E.M.; Beelen, S.; Verschueren, T.; Sobott, F.; Strelkov, S.V.; Weeks, S.D. The preferential heterodimerization of human small heat shock proteins hspb1 and hspb6 is dictated by the n-terminal domain. Arch. Biochem. Biophys. 2016, 610, 41-50. [CrossRef] [PubMed]

35. Kim, M.V.; Seit-Nebi, A.S.; Marston, S.B.; Gusev, N.B. Some properties of human small heat shock protein hsp22 (h11 or hspb8). Biochem. Biophys. Res. Commun. 2004, 315, 796-801. [CrossRef] [PubMed]

36. Rambo, R.P.; Tainer, J.A. Accurate assessment of mass, models and resolution by small-angle scattering. Nature 2013, 496, 477-481. [CrossRef] [PubMed]

37. Delbecq, S.P.; Jehle, S.; Klevit, R. Binding determinants of the small heat shock protein, $\alpha \mathrm{b}$-crystallin: Recognition of the ixi motif. EMBO J. 2012, 31, 4587-4594. [CrossRef] [PubMed]

38. Koteiche, H.A.; Chiu, S.; Majdoch, R.L.; Stewart, P.L.; McHaourab, H.S. Atomic models by cryo-em and site-directed spin labeling: Application to the n-terminal region of hsp16.5. Structure 2005, 13, 1165-1171. [CrossRef] [PubMed]

39. Jehle, S.; Vollmar, B.S.; Bardiaux, B.; Dove, K.K.; Rajagopal, P.; Gonen, T.; Oschkinat, H.; Klevit, R.E. $\mathrm{N}$-terminal domain of alphaB-crystallin provides a conformational switch for multimerization and structural heterogeneity. Proc. Natl. Acad. Sci. USA 2011, 108, 6409-6414. [CrossRef] [PubMed]

40. McDonald, E.T.; Bortolus, M.; Koteiche, H.A.; McHaourab, H.S. Sequence, structure, and dynamic determinants of hsp27 (hspb1) equilibrium dissociation are encoded by the n-terminal domain. Biochemistry 2012, 51, 1257-1268. [CrossRef] [PubMed]

41. Rogalla, T.; Ehrnsperger, M.; Preville, X.; Kotlyarov, A.; Lutsch, G.; Ducasse, C.; Paul, C.; Wieske, M.; Arrigo, A.P.; Buchner, J.; et al. Regulation of hsp27 oligomerization, chaperone function, and protective activity against oxidative stress/tumor necrosis factor $\alpha$ by phosphorylation. J. Biol. Chem. 1999, 274, 18947-18956. [CrossRef] [PubMed]

42. Hansen, L.; Yao, W.; Eiberg, H.; Kjaer, K.W.; Baggesen, K.; Hejtmancik, J.F.; Rosenberg, T. Genetic heterogeneity in microcornea-cataract: Five novel mutations in cryaa, crygd, and GJA8. Investig. Ophthalmol. Vis. Sci. 2007, 48, 3937-3944. [CrossRef] [PubMed]

43. Devi, R.R.; Yao, W.; Vijayalakshmi, P.; Sergeev, Y.V.; Sundaresan, P.; Hejtmancik, J.F. Crystallin gene mutations in indian families with inherited pediatric cataract. Mol. Vis. 2008, 14, 1157-1170. [PubMed]

44. Graw, J.; Klopp, N.; Illig, T.; Preising, M.N.; Lorenz, B. Congenital cataract and macular hypoplasia in humans associated with a de novo mutation in cryaa and compound heterozygous mutations in P. Graefes Arch. Clin. Exp. Ophthalmol. 2006, 244, 912-919. [CrossRef] [PubMed]

45. Laurie, K.J.; Dave, A.; Straga, T.; Souzeau, E.; Chataway, T.; Sykes, M.J.; Casey, T.; Teo, T.; Pater, J.; Craig, J.E.; et al. Identification of a novel oligomerization disrupting mutation in cry $\alpha$ a associated with congenital cataract in a south australian family. Hum. Mutat. 2013, 34, 435-438. [CrossRef] [PubMed]

46. Javadiyan, S.; Craig, J.E.; Souzeau, E.; Sharma, S.; Lower, K.M.; Pater, J.; Casey, T.; Hodson, T.; Burdon, K.P. Recurrent mutation in the crystallin $\alpha$ a gene associated with inherited paediatric cataract. BMC Res. Notes 2016, 9, 83. [CrossRef] [PubMed]

47. Kim, M.V.; Kasakov, A.S.; Seit-Nebi, A.S.; Marston, S.B.; Gusev, N.B. Structure and properties of k141e mutant of small heat shock protein hsp22 (hspb8, h11) that is expressed in human neuromuscular disorders. Arch. Biochem. Biophys. 2006, 454, 32-41. [CrossRef] [PubMed] 
48. Sluchanko, N.N.; Chebotareva, N.A.; Gusev, N.B. Quaternary structure of human small heat shock protein hspb6 (hsp20) in crowded media modeled by trimethylamine n-oxide (tmao): Effect of protein phosphorylation. Biochimie 2015, 108, 68-75. [CrossRef] [PubMed]

49. Bukach, O.V.; Seit-Nebi, A.S.; Marston, S.B.; Gusev, N.B. Some properties of human small heat shock protein hsp20 (hspb6). Eur. J. Biochem. 2004, 271, 291-302. [CrossRef] [PubMed]

50. Chowdary, T.K.; Raman, B.; Ramakrishna, T.; Rao, C.M. Mammalian hsp22 is a heat-inducible small heat-shock protein with chaperone-like activity. Biochem. J. 2004, 381, 379-387. [CrossRef] [PubMed]

51. Villen, J.; Beausoleil, S.A.; Gerber, S.A.; Gygi, S.P. Large-scale phosphorylation analysis of mouse liver. Proc. Natl. Acad. Sci. USA 2007, 104, 1488-1493. [CrossRef] [PubMed]

52. Shemetov, A.A.; Seit-Nebi, A.S.; Gusev, N.B. Phosphorylation of human small heat shock protein hspb8 (hsp22) by erk1 protein kinase. Mol. Cell. Biochem. 2011, 355, 47-55. [CrossRef] [PubMed]

53. Mymrikov, E.V.; Daake, M.; Richter, B.; Haslbeck, M.; Buchner, J. The chaperone activity and substrate spectrum of human small heat shock proteins. J. Biol. Chem. 2017, 292, 672-684. [CrossRef] [PubMed]

54. Vos, M.J.; Kanon, B.; Kampinga, H.H. Hspb7 is a sc35 speckle resident small heat shock protein. Biochim. Biophys. Acta 2009, 1793, 1343-1353. [CrossRef] [PubMed]

55. Shi, J.; Koteiche, H.A.; McHaourab, H.S.; Stewart, P.L. Cryoelectron microscopy and epr analysis of engineered symmetric and polydisperse hsp16.5 assemblies reveals determinants of polydispersity and substrate binding. J. Biol. Chem. 2006, 281, 40420-40428. [CrossRef] [PubMed]

56. Van de Klundert, F.A.; Smulders, R.H.; Gijsen, M.L.; Lindner, R.A.; Jaenicke, R.; Carver, J.A.; de Jong, W.W. The mammalian small heat-shock protein hsp20 forms dimers and is a poor chaperone. Eur. J. Biochem. 1998, 258, 1014-1021. [CrossRef] [PubMed]

57. Studier, F.W. Protein production by auto-induction in high density shaking cultures. Protein Expr. Purif. 2005, 41, 207-234. [CrossRef] [PubMed]

58. Mymrikov, E.V.; Seit-Nebi, A.S.; Gusev, N.B. Heterooligomeric complexes of human small heat shock proteins. Cell Stress Chaperones 2012, 17, 157-169. [CrossRef] [PubMed]

59. Laemmli, U.K. Cleavage of structural proteins during the assembly of the head of bacteriophage T4. Nature 1970, 227, 680-685. [CrossRef] [PubMed]

60. Lebowitz, J.; Lewis, M.S.; Schuck, P. Modern analytical ultracentrifugation in protein science: A tutorial review. Protein Sci. 2002, 11, 2067-2079. [CrossRef] [PubMed]

61. David, G.; Perez, J. Combined sampler robot and high-performance liquid chromatography: A fully automated system for biological small-angle x-ray scattering experiments at the synchrotron soleil swing beamline. J. Appl. Crystallogr. 2009, 42, 892-900. [CrossRef]

62. Alshammari, E.M.; Khan, S.; Jawed, A.; Adnan, M.; Khan, M.; Nabi, G.; Lohani, M.; Haque, S. Optimization of extraction parameters for enhanced production of ovotransferrin from egg white for antimicrobial applications. BioMed Res. Int. 2015, 2015, 934512. [CrossRef] [PubMed]

63. Evans, R.W.; Holbrook, J.J. Differences in the protein fluorecence of the two iron(iii)-binding sites of ovotransferrin. Biochem. J. 1975, 145, 201-207. [CrossRef] [PubMed]

64. Weeks, S.D.; Muranova, L.K.; Heirbaut, M.; Beelen, S.; Strelkov, S.V.; Gusev, N.B. Characterization of human small heat shock protein hspb1 $\alpha$-crystallin domain localized mutants associated with hereditary motor neuron diseases. Sci. Rep. 2018, 8, 688. [CrossRef] [PubMed]

(C) 2018 by the authors. Licensee MDPI, Basel, Switzerland. This article is an open access article distributed under the terms and conditions of the Creative Commons Attribution (CC BY) license (http:/ / creativecommons.org/licenses/by/4.0/). 